\title{
I 094 Normal left ventricular structure and function: inflection point in age effects
}

\author{
Dipti Gupta*, Sunil T Mathew, Deepu Alexander, William Schapiro, \\ Jing Han, Michael Passick, Mark J Goldman and Nathaniel Reichek
}

Address: St. Francis Hospital, Roslyn, NY, USA

* Corresponding author

from I th $^{\text {th }}$ Annual SCMR Scientific Sessions

Los Angeles, CA, USA. I-3 February 2008

Published: 22 October 2008

Journal of Cardiovascular Magnetic Resonance 2008, I0(Suppl I):A2 I9 doi:I0.II86/I532-429X-I0-SI-A2 I9

This abstract is available from: http://jcmr-online.com/content/I0/SI/A2I9

(C) 2008 Gupta et al; licensee BioMed Central Ltd.

\section{Background}

Existing studies of normal left ventricular (LV) structure and function using contemporary CMR methods (SSFP) are limited either in sample size, age range or verification of normality. Therefore we evaluated LV structure and function in a large, extensively screened cohort over a wide age range.

\section{Methods}

Normotensive, non-diabetic, non-obese (BMI < 28) volunteers ( $\mathrm{n}=218,119$ females), aged 20-89, were screened by 2D echocardiography and CMR was performed using SSFP cine imaging with contiguous $8 \mathrm{~mm}$ slices in the LV short axis plane. LV volumes (EDV, ESV), ejection fraction (EF) and mass $(\mathrm{M})$ were determined and indexed (i) to body surface area. (Medis, MASS).

\section{Results}

Women had higher EF and lower EDVi, ESVi and LVMi compared to men. With increasing age, systolic blood pressure increased, EDVi and ESVi decreased, EF increased, LVMi did not show a clear trend and LVMi/ EDVi increased. However, there was an inflection point at age 50, with EDVi, ESVi and systolic blood pressure for each decade $>50$ differing significantly from all decades $<50$ but no differences among decades $<50$ or $>50$ years. (Table 1.)

\section{Conclusion}

Age and blood pressure related concentric remodeling results in reduced chamber volumes and increased $\mathrm{EF}$ in presence of constant LV mass in both men and women. There is an inflection point at age 50 when chamber volumes fall and blood pressure increases in both genders. Further studies are needed to determine the physiologic basis of changes occurring in LV structure and function at age 50 . 
Table I:

\begin{tabular}{|c|c|c|c|c|c|c|c|c|c|c|c|c|}
\hline \multirow[t]{2}{*}{ Variable } & \multicolumn{7}{|c|}{ Pooled $(n=2 \mid 8)$} & \multicolumn{3}{|c|}{ Female $(n=119)$} & \multicolumn{2}{|l|}{ Male $(n=99)$} \\
\hline & $20-30$ *** & $30-40$ & $40-50$ & $50-60$ & $60-70$ & $70+$ & $\mathrm{P}$ & $<50(n=45)$ & $>=50(n=74)$ & $\mathrm{P}$ & $<50(\mathrm{n}=38)$ & $\mathrm{P}$ \\
\hline LVEDVi & $74.7^{*}$ & 77.2 & 78.2 & 66.8 & 66.5 & 62.8 & $<.0001$ & 74 & 63 & $<.0001$ & 81 & $<.0001$ \\
\hline LVESVi & 32.9 & 33.6 & 32.6 & 26.6 & 26.6 & 24.7 & $<.0001$ & 30 & 24 & $<.0001$ & 37 & $<.0001$ \\
\hline LVEF & 56.1 & 56.6 & 58.6 & 60.2 & 59.9 & 61.1 & 0.02 & 60 & 62 & 0.04 & 55 & 0.002 \\
\hline LVMi/EDVi & 0.7 & 0.7 & 0.7 & 0.9 & 0.9 & 0.8 & $<.0001$ & 0.7 & 0.9 & $<.0001$ & 0.8 & $<.0001$ \\
\hline SBP & 113 & 114 & 114 & $12 \mid$ & 122 & 126 & $<.0001$ & 111 & 121 & $<.0001$ & 116 & 0.0001 \\
\hline
\end{tabular}

*Mean values **Age in years $\cdot$ Systolic blood pressure

Publish with Bio Med Central and every scientist can read your work free of charge

"BioMed Central will be the most significant development for disseminating the results of biomedical research in our lifetime. "

Sir Paul Nurse, Cancer Research UK

Your research papers will be:

- available free of charge to the entire biomedical community

- peer reviewed and published immediately upon acceptance

- cited in PubMed and archived on PubMed Central

- yours - you keep the copyright 